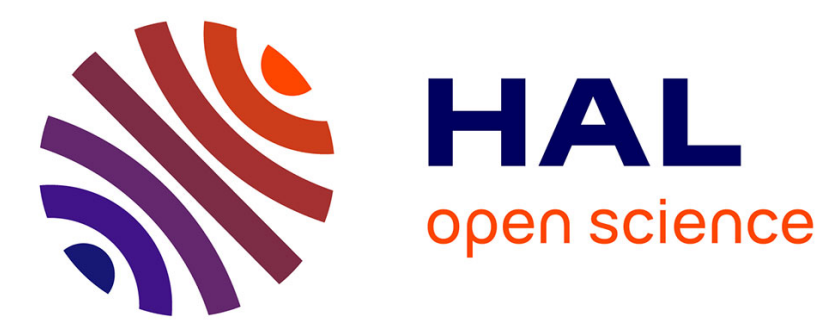

\title{
Modelisation of dynamic crack propagation criteria
}

T. Karimzada, H. Maigre

\section{To cite this version:}

T. Karimzada, H. Maigre. Modelisation of dynamic crack propagation criteria. Journal de Physique IV Proceedings, 2000, 10, pp.461-466. 10.1051/jp4:2000977 . hal-00111317

\section{HAL Id: hal-00111317 https://hal.science/hal-00111317}

Submitted on 15 Aug 2019

HAL is a multi-disciplinary open access archive for the deposit and dissemination of scientific research documents, whether they are published or not. The documents may come from teaching and research institutions in France or abroad, or from public or private research centers.
L'archive ouverte pluridisciplinaire HAL, est destinée au dépôt et à la diffusion de documents scientifiques de niveau recherche, publiés ou non, émanant des établissements d'enseignement et de recherche français ou étrangers, des laboratoires publics ou privés. 


\title{
Modelisation of dynamic crack propagation criteria
}

\author{
T. Karimzada and H. Maigre \\ Laboratoire de Mécanique des Solides, École Polytechnique, UMR du CNRS, ENPC, ENSMP, \\ 91128 Palaiseau cedex, France
}

\begin{abstract}
The aim of this study is the analysis of the dynamic crack propagation criteria in materials under impact loading. We want to define which mechanical quantities monitor the propagation, then use these parameters in numerical simulations and finally compare the results with dynamic propagation experiments. First, we propose a 1D semi-analytical model. In this model several mechanical quantities can be used to define the propagation criterion, like the energy release rate... The effect of the applied loading and the reflections of waves is also very important, leading sometimes to a stick-slip propagation. Next, we present a $2 \mathrm{D}$ modelisation. In this case, it is not possible to study analytically the effect each criterion and we need to use a numerical simulation. We propose a numerical method based on finite element. The propagation is simulated by releasing nodes with a the release criterion defined from the propagation criterion. The numerical scheme is chosen to respect the equivalence between the total dissipation and the fracture dissipation. In parallel, we have performed dynamic propagation experiments on PMMA. The samples are DCB specimens loading with a wedge in a Kolsky set-up. During each test, the location of the crack has been recorded 4 times with high speed cameras ( 1 microsecond shutter).
\end{abstract}

\section{INTRODUCTION}

Cracks in structures are always sources of failure particularly when the loading is transient. It is know that dynamic loading affects the toughness of materials but experiments giving precise measurement of the dynamic stress intensity factor at the onset of the propagation are difficult to achieve [1]. Moreover it is not clear that the dynamic toughness is directly related to the dynamic stress intensity factor and one can imagine a relation depending on the whole evolution of the stress at the crack tip till the initiation. After initiation, the study of the dynamic propagation is much more complicated for both aspects theoretical and experimental. For example, the mechanical state at the crack-tip is controlled by two intensity factors: a stress one $\mathrm{K}_{\mathrm{I}}{ }^{\sigma}$ and a kinematical one $\mathrm{K}_{\mathrm{I}}{ }^{\mathrm{u}}$ [2]. The parameters governing the propagation must also depend on the thermal heating appearing at the crack-tip because of the large amount of dissipated energy released to fracture the material in a very short time [3,4].

The aim of the present study is to propose different tools to analyse the dynamic propagation of cracks especially the interaction between the loading and the crack-tip, the dependence of the criteria on the crack speed and the thermo-mechanical coupling. The first one consists in a 1-Dimensional model [5, 6]. With this model the relation between the applied loading and the mechanical state at the crack-tip is obtained analytically and the propagation is a solution of a scalar differential equation depending only on the criteria. The second one is 2-Dimensional approach with dynamic propagation experiments coupled with numerical simulations.

\section{1-DIMENSIONAL MODEL}

\subsection{Modelisation}

We consider an elastic DCB structure subjected only to transversal displacements. We assume also that the stress state is defined by a shear force only. For example this modelisation can be applied to fiber 
composite where axial deformation is negligible compared to transverse distortion. Due to symmetry we just consider the upper half of the DBC. We note $u(x, t)$ the transverse displacement, $T(x, t)$ the internal shear, $a(t)$ the length of the crack and $F(t)$ the applied loading at the extremity $x=0$ of the DCB (figure 1).

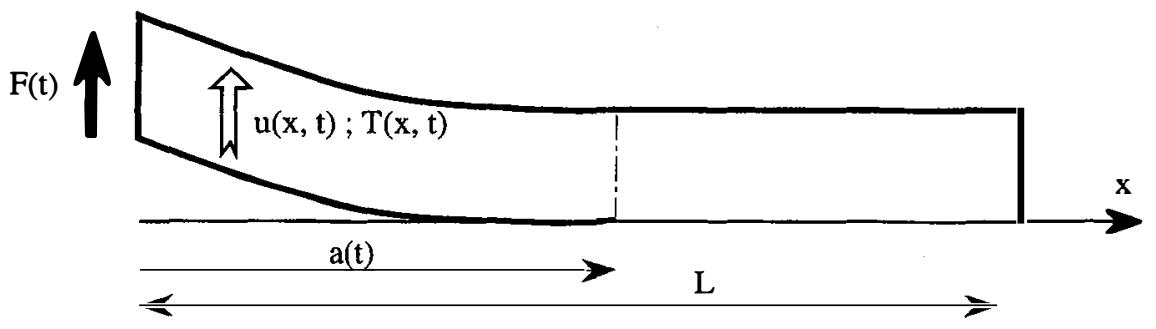

Figure 1. Upper half DCB model.

The equations governing this problem are the elastic behaviour and the equation of motion :

$$
\begin{aligned}
T(x, t) & =\mu S u_{. x}(x, t) \\
T(x, t)_{, x} & =\rho S u_{, t t}(x, t)
\end{aligned}
$$

$\mu S$ and $\rho S$ are respectively the elastic shearing modulus and the density of the material considered for this structure.

\subsection{Initial and boundary conditions}

Before solving the problem we need to fixe initial and boundary condition. Initially we suppose the DCB at rest so we have :

$$
\mathrm{T}(\mathrm{x}, \mathrm{t})=0 ; \mathrm{u}(\mathrm{x}, \mathrm{t})=0 \quad \forall \mathrm{x} \in[0 ; \mathrm{L}], \forall \mathrm{t}<0
$$

In $x=0$ we apply a given force $F(t)$ which is supposed to be inactive in the past and it is related to the shear force by the following condition:

$$
\mathrm{T}(0, \mathrm{t})=-\mathrm{F}(\mathrm{t}) \quad \forall \mathrm{t}
$$

Note that by convention when the crack is opening the shear force $\mathrm{T}$ is negative.

Normally we should prescribe a boundary condition in $\mathrm{x}=\mathrm{L}$. In our case the DCB is free along the crack and totally fixed after the crack-tip:

$$
\mathrm{u}(\mathrm{x}, \mathrm{t})=0 \quad \forall \mathrm{x} \in[\mathrm{a}(\mathrm{t}) ; \mathrm{L}], \forall \mathrm{t}
$$

The second boundary condition is then written like this:

$$
\mathrm{u}(\mathrm{a}(\mathrm{t}), \mathrm{t})=0 \quad \forall \mathrm{t}
$$

A special attention have to be paid on this condition because this a moving condition with the crack propagation depending on the crack length which is also an unknown variable of the problem.

\subsection{Criteria of propagation}

The evolution of the crack length depends on the criterion of propagation chosen at the crack-tip. With this 1-D model there is no stress singularity and therefore no stress intensity factors to quantify the 
loading of the crack. To define this loading we calculate the energy release rate $G(t)$ which is defined whatever the mechanical model of fracture is. In our case we finally obtained the following expression:

$$
\mathrm{G}(\mathrm{t})=\frac{1}{\mu \mathrm{S}} \mathrm{T}^{-}(\mathrm{t})^{2}\left(1-\frac{\dot{\mathrm{a}}^{2}}{\mathrm{c}^{2}}\right)
$$

Where $\left.T^{-}(t)=T\left(a^{-}(t), t\right)\right)$ is the shear force just before the crack-tip and $c=\sqrt{\mu S / \rho S}$ the celerity of the elastic shear waves in the DCB.

The shear force is not continuous at the moving crack-tip and the jump is obtained using shock wave relation which leads to the definition of the shear force in front of the crack-tip:

$$
\mathrm{T}^{+}(\mathrm{t})=\mathrm{T}\left(\mathrm{a}^{+}(\mathrm{t}), \mathrm{t}\right)=\mathrm{T}\left(\mathrm{a}^{-}(\mathrm{t}), \mathrm{t}\right)-\frac{\dot{\mathrm{a}}^{2}}{\mathrm{c}^{2}} \mathrm{~T}\left(\mathrm{a}^{-}(\mathrm{t}), \mathrm{t}\right)=\mathrm{T}^{-}(\mathrm{t})\left(1-\frac{\dot{\mathrm{a}}^{2}}{\mathrm{c}^{2}}\right)
$$

Putting this result in the definition of $\mathrm{G}$ we obtain :

$$
G(t)=\frac{1}{\mu S} T^{\prime \prime}(t) T^{+}(t)
$$

This expression is very similar to the expression given in the 2-dimensional model with two stress intensity factors, the stress intensity factor and the kinematic intensity factor.

So in our model a criterion of propagation will appear as a function of these four quantities $\left(\mathrm{G}, \mathrm{T}^{-}\right.$, $\left.\mathrm{T}^{+}, \dot{\mathrm{a}}\right)$ in which only two of them are really independent.

\subsection{Equation of propagation}

The general solution of equation (1) and (2) is a set of two unknown scalar functions $f$ and $g$ :

$$
\mathrm{u}(\mathrm{x}, \mathrm{t})=\mathrm{f}(\mathrm{t}-\mathrm{x} / \mathrm{c})+\mathrm{g}(\mathrm{t}+\mathrm{x} / \mathrm{c})
$$

Putting this expression in the initial and the boundary conditions we find a explicit relation between the applied loading and the criterion of propagation. This relation gives a non linear differential equation of the first order on $\mathrm{a}(\mathrm{t})$. In the first stage $\left(\mathrm{t}<\mathrm{t}_{1}\right)$ when we consider the arrival of the first incident wave this equation becomes:

$$
\mathrm{T}^{-}(\mathrm{t})=\mathrm{T}(\mathrm{a}(\mathrm{t}), \mathrm{t})=-2 \frac{\mathrm{F}(\mathrm{t}-\mathrm{a}(\mathrm{t}) / \mathrm{c})}{1+\dot{\mathrm{a}} / \mathrm{c}} \quad \forall \mathrm{t}<\mathrm{t}_{1}
$$

After a certain time $\left(t_{1}<t\right)$ reflected waves at the crack-tip and at the extremity $x=0$ will arrive again at the crack-tip and perturb the propagation. The new differential equation is:

$$
\mathrm{T}(\mathrm{a}(\mathrm{t}), \mathrm{t})=-2 \frac{\mathrm{F}(\mathrm{t}-\mathrm{a}(\mathrm{t}) / \mathrm{c})-\mathrm{F}_{1}(\mathrm{t})}{1+\dot{\mathrm{a}} / \mathrm{c}} \quad \forall \mathrm{t}>\mathrm{t}_{1}
$$

Where $F_{1}(t)$ is a known function depending on the previously calculated evolution of the crack propagation.

\subsection{Numerical illustrations}

We present two examples of propagation obtained with this model. In these examples the load applied is linear increasing force and we compare two criteria of propagation. The first one is defined by a critical release rate value $G_{c}$ as:

$$
\dot{\mathrm{a}}=0 \text { if } \mathrm{G}(\mathrm{t})<\mathrm{G}_{\mathrm{C}} \text { and } \mathrm{G}(\mathrm{t})=\mathrm{G}_{\mathrm{C}} \text { if } \dot{\mathrm{a}}>0
$$

The second one is defined by a critical shear force value $T_{C}$ as: 


$$
\dot{\mathrm{a}}=0 \quad \text { if }-\mathrm{T}^{+}(\mathrm{t})<\mathrm{T}_{\mathrm{C}} \text { and }-\mathrm{T}^{+}(\mathrm{t})=\mathrm{T}_{\mathrm{C}} \text { if } \dot{\mathrm{a}}>0
$$

We consider this second criterion because in the 2-dimensional model it will correspond to a critical stress intensity factor.

All dimensions are taken to 1 , so the initial crack length is 1 , the elastic celerity is $1, \ldots$ The critical values are also taken to 1 . The applied force is $F(t)=0.5+0.4 \mathrm{t}$ so that the propagation just initiates at the arrival of the first wave at the crack-tip. The main result is plotted on the graph figure 2 .

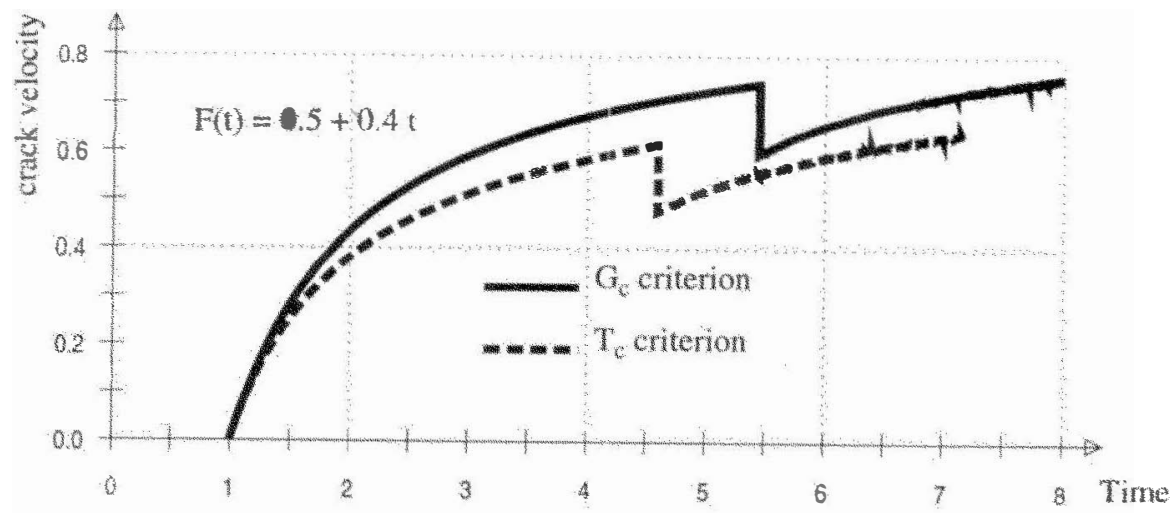

Figure 2 Evolution of the crack velocity for two different criteria of propagation

We can see in both case that the celerity is always lower than 1 which the maximum theoretical celerity. Even if the applied load is increasing continuously reflections at the crack-tip produce a sudden decrease of the crack velocity. The difference between $\mathrm{G}_{\mathrm{C}}$ criterion and $T_{\mathrm{C}}$ criterion is not very important, the first one just leads to faster crack propagation.

\section{Dynamic propagation experiments}

\subsection{Experimental setup}

Our experimental setup consists of DCB specimens placed between split Hopkinson pressure bars (SHPB). The opening of the crack is obtained with a $90^{\circ}$ wedge (figure 3 ). Bars are made of maraging and specimen of PMMA. The specimens are transparent and we used 4 electronic high speed camera to take 4 micro-second pictures during test at 4 different moments.

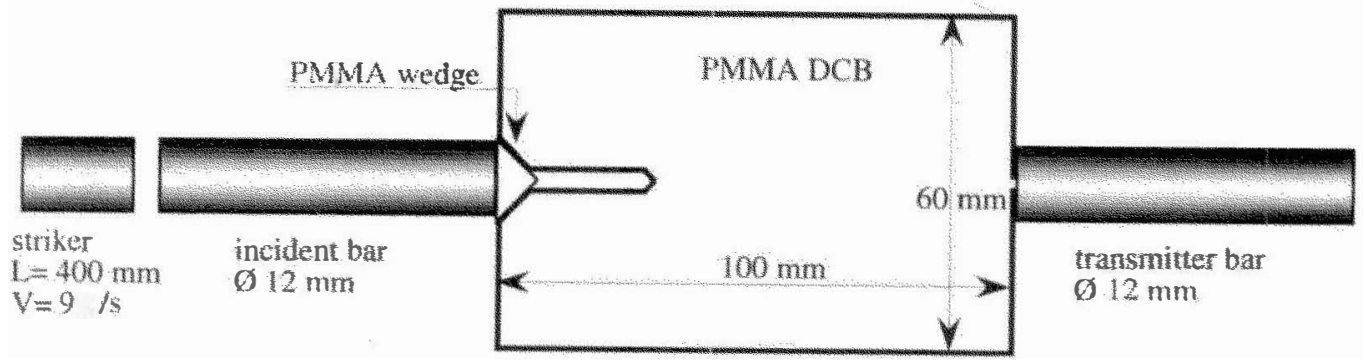

Figure 3. SHPB setup with DCB specimen loaded with a wedge 
The initial crack length is $28 \mathrm{~mm}$ so the crack can dynamically propagate over $70 \mathrm{~mm}$. We did 4 experiments with roughly the same impact loading. The velocity of the striker was between $9 \mathrm{~m} / \mathrm{s}$ and $9.7 \mathrm{~m} / \mathrm{s}$ and the force applied to the wedge was about $8 \mathrm{kN}$ at the maximum for a duration of $200 \mu \mathrm{s}$. We put grease between the wedge and the specimen and we assume a non frictional contact.

\subsection{Experimental results}

Theoretically the cracks should propagate along symmetric plane of the specimen. In fact we observe the symmetry in the beginning of the propagation $(\sim 25 \mathrm{~mm})$ and then a slight and smooth deviation occurs. This is due mainly to the non perfectly symmetric contact between the specimen and the bars (figure 4).

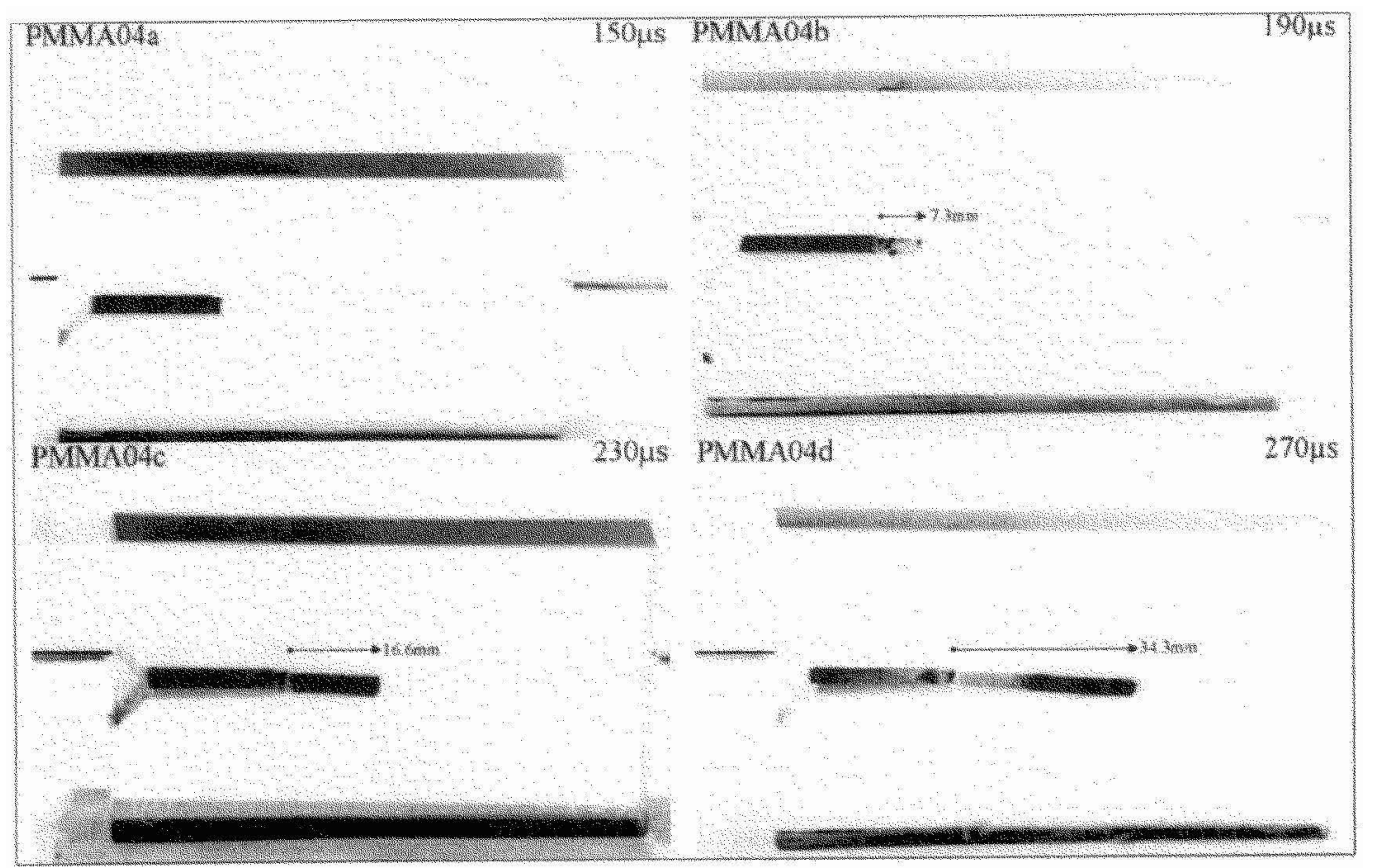

Figure 4. Four $\mu$ s pictures showing the position of the crack during a dynamic propagation.

As we did 4 tests under the same loading we obtained 16 pictures taken at 16 different moments. If we assume the reproductibility of the experiments we have 16 different positions of the crack (figure 5). We can observe a regular propagation of the crack with a slight acceleration at $220 \mu \mathrm{s}$. The average celerity is $370 \mathrm{~m} / \mathrm{s}$. The loading entering the specimen at $120 \mu \mathrm{s}$, propagation starts $30 \mu \mathrm{s}$ after and lasts $200 \mu \mathrm{s}$. These durations are to be compared to $40 \mu \mathrm{s}$ which is the time for the elastic waves to go from the incident bar to the transmitter bar. So it seems that the crack propagation is not affected by the reflections on the boundaries of the specimen. The examination of the crack surfaces shows the commonly observed feature of conical markings. More precisely we can see a rather mirror aspect at the beginning and a rather rough feature after which is in agreement with the observed acceleration. 


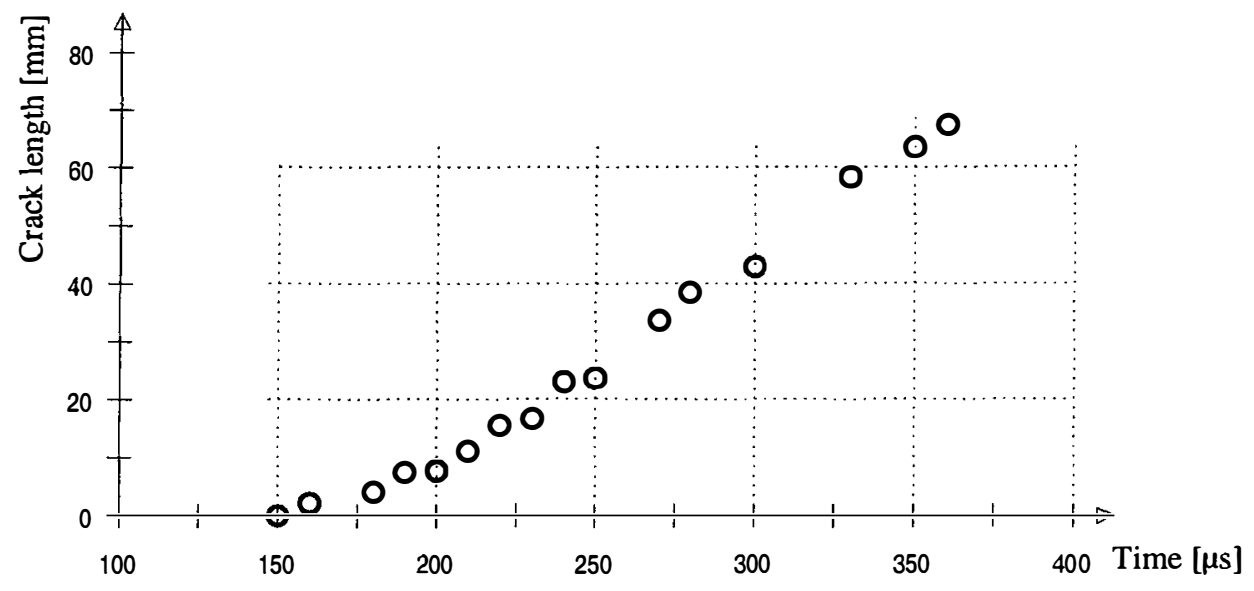

Figure 5. Crack position as function of time in 4 dynamic propagation tests

\subsection{Numerical simulation}

As we did not have photoelasticity or caustic facilities to measure directly the dynamic stress intensity factors we need to simulate numerically the previous experiments to investigate the a representative criterion of propagation. A first numerical simulation has been done using an elasto-dynamic finiteelement method. In these simulations the input forces are the experimental data got from the SHPB records and the propagation was simulated by releasing the nodal force at the crack-tip according to the experimental observation. The numerical result is the energy release rate $\mathrm{G}$ as function of time computed using path invariant integral. We have obtained a lot of oscillations around a roughly constant average value during the propagation. These oscillations come essentially from the numerical technique used to perform the propagation. In the 1D model we obtained regular propagation with some jumps of celerity corresponding to particular reflected waves. In the experiments there should be some sudden variation but not at each time step. The next step will consist in simulating the propagation with a given criterion and find the one giving a numerical crack propagation close to the experimental one.

\section{Conclusions}

We have presented some preliminary results on dynamic propagation of cracks. Theses results are based on a semi-analytical 1-Dimensional model and on 2-Dimensional experiments. The 1D model gives exact results on the condition of propagation as a function of the criterion. Theses $1 \mathrm{D}$ results are very useful to find the right way to perform $2 \mathrm{D}$ simulations which are the only way to analyze carefully propagation experiments.

\section{References}

[1] Rosakis A. J. and Ravichandran G., Int. J. Solids Structures 37 (2000) 331-348.

[2] Achenbach J. D. and Bazant Z. P., J. Appl. Mech. 42 (1975) 183-189.

[3] Bui H. D., Ehrlacher A. and Nguyen Q. S., J. Méca. 19 (1980) 697.

[4] Rittel D., Int. J. Solids Structures 35 (1998) 2959-2973.

[5] Kanninen M. F., Int. J. Fract. 10 (1974) 415-430.

[6] Mannion L., Quat. Appl. Math. XLV (1987) 713-719. 